\title{
El léxico zoológico para referirse a los amantes en las Coplas del amor feliz del Cancionero Folklórico de México ${ }^{1}$
}

\author{
The zoological lexicon that refers to lovers \\ in Coplas del amor feliz of Cancionero \\ Folklórico de México
}

\author{
Alfonso Padrón Martínez \\ El Colegio de México \\ alfonsop52@gmail.com
}

Resumen

Este trabajo analiza el léxico con referentes zoológicos (mamíferos, aves, animales marinos e insectos) utilizado para referir a la amada en 1,995 coplas del Cancionero Folklórico de México. Se asume que los hablantes dan cuenta del contexto situacional y cultural en el que se encuentran a partir del uso de cierto léxico durante el proceso de creación de las coplas. A la luz de los datos analizados, se encontró que dentro de la poética de la lírica popular mexicana se dan procesos de metaforización, con el objetivo de referir a la amada de manera directa o bien indirecta, otorgándole cualidades zoológicas a partir de uno de sus rasgos humanos (boca, brazos, voz y cuerpo/apariencia).

Palabras Clave: lírica popular mexicana, léxico zoológico, metaforización, cancionero, poética

\section{Abstract}

This paper analyzes the lexicon with zoological references (mammals, birds, ocean animals and insects) used to refer to the beloved in 1995 coplas of the Mexican Folk Cancionero. It is assumed that the speakers give an account of the situational and cultural context in which they find themselves from the use of a certain lexicon during the process of creating the coplas. In the light of the data analyzed, it was found that within the poetics of the popular Mexican lyric there are processes of metaphorization, with the aim of referring the beloved in a direct or indirect way, granting her zoological qualities from one of his features (mouth, arms, voice and body/appearance).

KEYwORDS: mexican folk lyrics, zoological lexicon, metaphorization, cancionero, poetics

\footnotetext{
${ }^{1}$ Agradezco el apoyo y la motivación para publicar este trabajo a la doctora María Ángeles Soler Arechalde y al doctor Erik Franco; también, mi agradecimiento por su confianza a María Campos Guardado.
} 
FECHA DE RECEPCIÓN: 07/09/2018

FECHA DE ACEPTACIÓN: 14/02/2019

\section{Introducción}

El léxico no solo es el "conjunto de las palabras de un idioma" como lo define el Diccionario de la Real Academia Española en la cuarta acepción, sino que es un reflejo de la cultura de una sociedad en un tiempo y espacio determinado. Cada una de las formas para designar una entidad en la realidad es producto de la experiencia de los hablantes y, en consecuencia, cada acto de denominación implica tanto un proceso de referencialidad como uno de conceptualización, es decir, la manera en que el hablante genera una serie de categorías e ideas en relación con las entidades, y así hacer uso de las palabras en varios contextos (Lara, 2016: 15-51).

Ahora bien, uno de los temas que más aparece reflejado en la lírica popular es el amor. ${ }^{2}$ Esto no es algo excepcional, pues a diferencia de la narrativa folklórica, en la que se cuentan las historias de los héroes y sus hazañas, o de alguna batalla importante, la poesía lírica se recrea en los sentimientos. En todo caso, uno de los elementos indispensables en el tema amoroso es la mujer, pues sin una mujer, el hombre-cantante ${ }^{3}$ no tiene a quién dedicar las canciones, versos sueltos o cualquier otra expresión

\footnotetext{
${ }^{2}$ Para comprobar lo anterior, basta asomarse al Cancionero Folklórico de México, el cual está dividido, a partir de los materiales, en dos grandes grupos a) coplas amatorias y b) coplas no amatorias; de las primeras se ocupan los tomos 1, 2 y parte del 3 , en cambio de las segundas solo el 4 y la mayoría de las canciones antologadas en el tomo 5.

${ }^{3} \mathrm{Al}$ decir hombre-cantante me refiero al hecho de que en la mayoría de los casos es una voz masculina la que aparece en la lírica popular amatoria y por ello es muy posible que los primeros autores de versos y cancioncillas hayan sido hombres (trovadores, troveros, juglares), aunque también se ha atribuido un autor femenino a ciertas composiciones a partir del mismo argumento de la voz poética; para más información sobre este problema de autorías masculina o femenina véase Frenk, 1985.
} 
folklórica. Durante la creación poética, el autor siempre buscará alguna forma de referirse a su amada, sea de manera directa (nombre) o indirecta (alusión metafórica), y es en este juego de denominaciones en el que el léxico se vuelve un elemento clave para lograr el objetivo de apelar a la mujer.

Con base en lo expresado anteriormente sobre el papel del léxico en la denominación de la amada y el amante en la lírica popular y bajo el supuesto de que el léxico refleja la visión de mundo de una sociedad, este trabajo, a partir de la manera como se articula el léxico de la zoología para referirse a los amantes, busca dar respuesta a las siguientes preguntas: ¿cuál es el léxico utilizado en la lírica folklórica mexicana para referirse a la amada? ${ }^{4}$ ¿Qué revela dicho vocabulario de la cultura amorosa en México? ¿Cuáles son las características formales y semánticas de este tipo de léxico?

\subsection{Conformación del corpus y metodología}

El corpus para esta investigación se compone de 1,995 coplas ${ }^{5}$ del tomo 1. Coplas del Amor Feliz, sección "El Amante habla a la Amada” del Cancionero Folklórico de México. La razón para esta selección se fundamenta en que, dentro de los objetivos del Cancionero:

Importaba, pues, reunir los materiales de la lírica folklórica diseminados en esas publicaciones [es decir, las recopilaciones de poesía

\footnotetext{
${ }^{4}$ Considero el léxico para referirse a la amada como una forma de tratamiento, es decir, una expresión que codifica las relaciones que existen entre emisor y receptor, un tipo de deixis social (Levinson, 1985: 89-92); así, las formas y fórmulas de tratamiento no solo tendrían que limitarse a las de cortesía (tú, usted, sumercé), también entrarían las de afecto (amor, corazón, mi vida), en las que se busca una mayor interrelación entre los participantes del acto comunicativo, e incluso las de sátira, como lo son los apodos en son de burla.

${ }^{5}$ Una copla es una cuarteta octosílaba, sin embargo, hay casos en los que está conformada de más o menos versos y no siempre se respeta la métrica (uso de versos de menos de ocho sílabas); para la historia de la copla como complejo temático formal y su evolución en la lírica hispánica véase Masera, 2007. Las 1,995 coplas que conforman el corpus de esta investigación se traducen en un aproximado de 7,980 versos y, a su vez, en un total de casi 31,920 palabras o unidades gráficas entre dos espacios.
} 
popular de Vázquez Santana, Rubén M. Campos, Francis Toor y de la Sociedad Folklórica de México]; pero además había que acudir a muchas otras fuentes, escritas y orales: colecciones manuscritas, hojas sueltas y cancionerillos de los que venden en ferias y puestos de periódicos, discos, y más que nada, las grabaciones magnetofónicas [...] Además había que explorar directamente la tradición oral, hasta donde esto fuera posible. El espacio geográfico que queríamos abarcar era todo el ámbito de la República Mexicana; el cronológico, el siglo xx (Frenk, 1985: xv-xvi).

Por lo tanto, el Cancionero se convierte así en un corpus representativo del estado lingüístico, poético y cultural del México popular del siglo xx; además de que presenta dentro de la edición datos útiles sobre las coplas, por ejemplo, lugar de procedencia, si se trata de una copla suelta o de una ya publicada en un cancionero, y si tiene variantes.

\subsection{Metodología}

La metodología que se siguió fue la de consignar toda ocurrencia de léxico zoológico - es decir, cualquier palabra que tenga por referente un mamífero, un ave, un animal marino o un insecto, o bien una parte física que refiera a uno de estos- que apareciera en las 1,995 coplas de la sección "El Amante habla a su Amada"; vgr.

(1) Una chuparrosa un día

hacia tus labios voló;

la pobrecita creía

que era rosa, y se engañó:

por eso te perseguía.

(64, La Rosita, Veracruz y San Luis Potosí) ${ }^{6}$

\footnotetext{
${ }^{6}$ Todas las coplas que cito son del tomo 1 del Cancionero, a partir de aquí solo consigno el número de copla, la canción de procedencia y el lugar de origen, si lo hay. Las cursivas son mías y las uso para resaltar el elemento (pluri)léxico que designa a un animal; el número entre paréntesis es para la numeración de todos los ejemplos en este trabajo.
} 
Después, como se verá en la sección "De los animales en general. Análisis cuantitativo", se llevó a cabo un análisis cuantitativo general del corpus, para dar cuenta de los diez vocablos zoológicos más frecuentes en la lírica popular mexicana, sea para referir al amante o a la amada, y se darán algunas particularidades semánticas sobre su uso; en seguida, en "La amada zoologizada. Análisis cualitativo", se presenta un análisis cualitativo específico que busca determinar qué palabras sirven para referirse a la amada de manera indirecta, es decir, mediante una metáfora como "encantada mariposa", y las que designen cualidades animales, por ejemplo "cuerpo de urraca", así como una interpretación semántica de los datos encontrados. Por último, en las conclusiones, se ofrece una explicación plausible para el uso y vigencia de dichos elementos en su uso poético, con base en una encuesta realizada por internet en la que se preguntó cómo se refieren las personas a su novio/esposo, a su novia/esposa, estando ellos presentes y al hablar sobre ellos. ${ }^{7}$

\section{De los animales en general. Análisis cuantitativo}

Dentro de las 1,995 coplas analizadas, solo en 206 (10.325\%) aparece al menos uno, y como máximo seis animales; dentro de este conjunto hay en total 248 ocurrencias de lexemas que designan un miembro del campo semántico de la zoología. ${ }^{8}$

\footnotetext{
${ }^{7}$ La encuesta se elaboró con la plataforma SurveyMonkey y se realizó entre el 8 y 16 de noviembre de 2017; el total de respuestas obtenidas fue de 163, de las cuales $83 \%$ pertenecen a mujeres y $17 \%$ a hombres. Los rangos de edad de los informantes fueron los siguientes: 18-20 (18\%), 21-29 (65\%), 30-39 (13\%) y 40-59 (4\%); el grado académico se repartió porcentualmente entre Preparatoria (35\%), Universidad (56\%) y Posgrado (9\%).

${ }^{8}$ Entiendo lexema como sinónimo de unidad gráfica separada por dos blancos, con la salvedad de que tenga que ser la unidad de denominación de algún miembro del campo de la zoología, sea mamífero, ave, animal marino o insecto. En todo el corpus, solo hay una copla en la que se utilizan seis palabras que designan animales; la mayoría de las cuartetas usa entre uno y dos elementos léxicos zoológicos. La explicación a este fenómeno es que en los casos en que solo aparece un animal se trata de una enunciación directa del locutor (el hombre) al alocutario (la mujer), y en los de dos se debe a que se hace una analogía entre los amantes y una pareja
} 
A continuación, se ejemplifica lo anterior; con la aparición de un animal:

(2) Eres mi prenda querida

y mi adorada señora,

eres el pájaro cú,

que canta al romper la aurora.

(97, El pájaro cú, Oaxaca y Veracruz)

\section{Con dos:}

(3) Tengo un amor en la peña y abajo en el planecito.

Si me has de querer, morena,

y ha de ser a mí solito:

no hagas lo de las gallinas,

que tapan cualquier pollito.

(996, Las flores, Hidalgo)

o bien,

(4) Cotorra del pico chueco,

prima hermana del perico,

si te pones tu plumita,

yo te llevo hasta Tampico.

(1308, El toro rabón, Guerrero)

\section{Con tres:}

(5) En la rama de aquel árbol cantaba una tortolita;

de animales (gavilán-paloma, gallina-pollito, guacamaya pinta-guacamaya azul). Dentro de la creación de la copla, la aparición de uno de estos lexemas puede ser usado para crear el locus amoenus, o escenario amoroso en la narración, y también como recurso rítmico para que el verso no quede cojo o como ayuda mnemotécnica al usar la terminación silábica de la palabra para que se logre la rima consonante, es decir, se activa la memoria semántica mediante la posibilidad de predecir qué palabras siguen en la estrofa. 
la arremedó un gorrión:

“iAh, qué muchacha bonita!,

quisiera ser tiburón

para tragármela enterita”.

(830, estrofa suelta)

No hay coplas en las que aparezcan cuatro o cinco animales, pero sí con seis, el único testimonio es el siguiente:

(6) La mariposa anhelante buscaba un cáliz de rosa, y en tus mejillas de grana (Llorona)

se fue a posar amorosa.

También se queja el cenzontle, porque robaste sus trinos, y las palomas y garzas, por tu seno alabastrino. Yo también, como el cenzontle, como esas flores y aves, siento celos, vida mía, y el motivo tú lo sabes. (52, La Llorona, Oaxaca)

Una vez realizado el análisis de ocurrencias por campo semántico, se encontraron 65 animales diferentes, que abarcan, según la tradición de los bestiarios medievales, los tres entornos naturales: bestias aéreas, bestias terrestres y bestias acuáticas o marinas. La mayoría de los que presenta el corpus pertenece al primer entorno, seguidos por los que habitan en tierra y, en minoría, los que viven en el agua. ${ }^{9}$

Ahora bien, revisemos los lexemas con mayor número de ocurrencias:

\footnotetext{
${ }^{9}$ Minoría extrema ya que solo aparecen sardina, tiburón y pescaditos, con 3,1 y 1 ocurrencias, respectivamente; ahora bien, puede considerarse también el lexema ballena (una vez) dentro del grupo de animales marinos, por el hecho de que los hablantes lo ubican más dentro de la categoría de peces que de mamíferos.
} 


\begin{tabular}{c|cc} 
Posición & Animal & Total de ocurrencias (absoluto-relativo) \\
\hline 1 & Paloma & $53-21.370 \%$ \\
2 & Pájaro $^{10}$ & $20-8.064 \%$ \\
3 & Guacamaya & $14-5.645 \%$ \\
4 & Ave & $13-5.241 \%$ \\
5 & Mariposa & $12-4.838 \%$ \\
6 & Águila & $8-3.225 \%$ \\
7 & Gavilán & $8-3.225 \%$ \\
8 & Calandria & $6-2.419 \%$ \\
9 & Pichón & $6-2.419 \%$ \\
10 & Ruiseñor & $6-2.419 \%$
\end{tabular}

Es interesante observar que, salvo por mariposa, todos los lexemas pertenecen al campo semántico de las aves. De estos, paloma, guacamaya, calandria y pichón pueden considerarse como el subgrupo de "inofensivas", mientras que águila y gavilán componen el de "aves de caza”. Esta subdivisión dentro del campo semántico revela dos visiones de la amada desde la perspectiva del amante: la primera es la "amada inofensiva", asociada con paloma y pichón, porque se trata de aves que resultan presas de un depredador, en este caso el amante, o bien destacan por su belleza o por poseer alguna cualidad física o habilidad singular, como calandria y guacamaya; la segunda subdivisión es la de "la amada superior", que a pesar de que está asociada con aves depredadoras, gavilán y águila, más bien estas analogías parecen hacer referencia a que se trata de una amada con un carácter

\footnotetext{
${ }^{10}$ Dado que se trata de un sustantivo genérico que puede tener a veces un adjetivo, no he considerado sintagmas como pájaro cú, pájaro cardenal, pájaro vilán (una ocurrencia en todos), ni pájaro barranqueño y pájaro concurrión (3 ocurrencias cada uno), porque considero que se trata de aves específicas más que una mera adjetivación para lograr la rima o dar un giro poético mediante una caracterización.
} 
fuerte, casi altiva, pues la enaltece su apariencia física y su moral es superior a lo esperado.

A esta decena le sigue con cinco ocurrencias (2.016\%), caballo; luego, con cuatro (1.612\%): cenzontle, chuparrosa, ${ }^{11}$ gallo, garza, perico, venado; con tres (1.209\%): coyote, pájaro concurrión, pájaro barranqueño, gato y sardina; con dos (0.806\%): cuitlacoche, gallina, jilguero, lagartijo, mariquita, mosquito, oveja, palomo, [perro] perdiguero, toro, urraca; finalmente, con una (0.403\%): abeja, alacrán, animalito, armadillo, ballena, cocuyo, cotorra, criatura, chachalaca, chapulín, golondrina, gorrión, grulla, hortelano, liebre, oso, pato, pescaditos, pijul, pipiola, pollito, [mirlo] primavera, potranca, potro, ratón, tórtolo y tiburón.

Del listado anterior destacan cuatro elementos:

1. el uso de genéricos no marcados, animalito y criatura, que refieren en la lírica popular a seres humanos, sea el amante o la amada, como en (7) y (8):

(7) En una cuna de alambre se mece un animalito; ándale, no seas cobarde, que mi amor no tiene grito; no tengo padre ni madre, vida mía, yo soy solito. (1087, La Malagueña, Michoacán)

(8) Cuando el cenzontle canta se me figura que es voz de tu garganta, linda criatura; y ha de ser cierto, porque si tú no cantas (cielito lindo), todo está muerto. (227, Cielito lindo, Veracruz)

\footnotetext{
${ }^{11}$ En el corpus aparece tanto chuparrosa como pájaro gurrión y colibrí; dado que designan sin distinción a las cuatro especies endémicas de México, decidí incluir las tres formas en una sola entrada (chuparrosa) que englobe todas las formas para referir a un único concepto.
} 
2. la poca cantidad de nahuatlismos; de hecho, solo son seis:

a) cenzontle: "Del náhuatl centzontli 'cuatrocientos' y tlatolli 'voz' [...]. Pájaro de la familia de los númidos, de color pardo y canto muy variado en el que llega a imitar los sonidos que producen otras aves y los seres humanos" (Soler Arechalde, 1998: s.v.).

(9) Tehuanita de mi vida,

no te apartes de mi lado;

tengo que darte un cenzontle

$\mathrm{y}$ un pájaro colorado.

(654, La Zandunga)

b) coyote: "Del náhuatl coyotl [...] Especie mexicana de lobo, del tamaño de un perro grande y pelaje de color gris amarillento" (Soler Arechalde, 1998: s.v.).

(10) Coyote, coyote, coyote dañero, échame los brazos, que por ti me muero. (1483, El coyote, Tabasco)

c) cuitlacoche o cuicacoche: "Del náhuatl cuicatl 'canto' y cochi 'dormir'; 'que canta para dormir' [...] Ave canora de la familia de los túrdidos, de plumaje amarillo en el pecho y vientre y negro o gris en el resto del cuerpo" (Soler Arechalde, 1998: s.v.).

(11) Pareces cuitlacochita, ¡quién tu cuitlacoche fuera!

Quisiera ser espinita de tu verde nopalera, para darte una espinadita cuando salgas para afuera. (827b, El indio) 
d) chachalaca: "Del náhuatl chachalaca 'parlar mucho o gorjear las aves' [...] Especie de gallina muy vocinglera de color pardo, con el vientre y las patas blancos; cola larga de plumas amarillentas; sin cresta ni barba y con los ojos rojos; su carne es muy estimada" (Soler Arechalde, 1998: s.v.).

(12) Eres chachalaca mía,

que no te puedo olvidar;

vente conmigo a la rama,

para poderte besar.

(1362, La chachalaca, Oaxaca)

e) chapulín: "Del náhuatl chapulli [...] Insecto acrídido, langosta, saltamontes" (Soler Arechalde, 1998: s.v.).

(13) Quisiera ser chapulín

para brincar en tu cama;

dos, tres, cuatro, cinco, en fin,

ya me voy, hasta mañana.

(794, Negra del alma, Oaxaca)

f) pipiola: "Del náhuatl pipiyolli [...] Especie de abeja muy pequeña" (DLE, s.v.). ${ }^{12}$

(14) Escucha, mi pipiolita, ya no quiero oírte llorar, y aunque tu mamá no quiera, nos tendremos que juntar.

Seguiremos el ejemplo de lo que es muy natural; viviremos muy juntitos, alegres en nuestro jacal. (1897, La pipiolita, Michoacán)

\footnotetext{
${ }^{12}$ Este es un caso de cognado, pues el Diccionario de la lengua española (DLE) registra tanto el vocablo procedente del náhuatl como el de procedencia latina pipiolo, pipiola, del diminutivo pipio, pipionis 'pichón, polluelo'.
} 
3. la aparición de otros insectos además de la mariposa: abeja, alacrán, cocuyo, chapulín, mariquita y mosquito, que no tienen un grupo bien definido dentro de los bestiarios. En cuanto a su función en el Cancionero, abeja y mariquita refieren a la mujer:

(15) Dices que no comes miel,

porque no eres abejita;

anoche que te besé

tenías dulce la boquita.

(1778, El ramo y El venadito, Oaxaca y Veracruz)

(16) Mariquita, quita, quita,

quítame de padecer;

el rato que no te veo

loco me quiero volver.

(835, Mariquita, quita, quita, Guerrero)

En el caso de (15) resalta la peculiaridad de que dentro de la cuarteta la decisión de mencionar a cierto tipo de insecto para referir a la mujer depende de la aparición de algún otro vocablo relacionado con el elemento zoológico en versos anteriores. Así, se establece la relación miel-abejita-mujer, a partir de la aparición de los dos elementos que ya tienen una relación per se: miel y abeja.

Cocuyo, mosquito y chapulín, mediante metáfora, aluden al hombre que busca ser como ellos y así tener una ventaja para estar con su amada; el primero por la capacidad de brillar y alumbrar el camino hacia la amada, ${ }^{13}$ los otros dos con clara connotación sexual: ${ }^{14}$

\footnotetext{
${ }^{13}$ Tanto el DLE como el Diccionario del español de México (DEM) destacan el hecho de que este insecto despide una luz azul o verdosa de gran intensidad. Esto refleja el proceso de valoración de las experiencias que los hablantes han tenido con el cocuyo y cómo es que este rasgo se ha vuelto parte inherente del significado tanto referencial como cultural (Lara, 2006: 100-101).

${ }^{14}$ De igual forma que con el cocuyo, las definiciones lexicográficas del DLE y del DEM toman como rasgo sine qua non para definir al mosquito como un insecto que pica.
} 
(17) ¡Quién fuera como el cocuyo, que alumbra para volar!

Dime qué amor es el tuyo, que no lo puedo olvidar; por más que lo disimulo, no dejo de sospirar. (408, estrofa suelta, Veracruz y Puebla)

(18) Quisiera ser mosquito, un mosquito retozón, $\mathrm{y}$ darle un piquetito en medio del corazón. (812, El mosquito)

(19) Quisiera ser chapulín para brincar en tu cama; dos, tres, cuatro, cinco, en fin, ya me voy, hasta mañana. (794, Negra del alma, Oaxaca)

El alacrán cumple la función narrativa de coadyuvante para que el amante pueda ir con su amada y sea salvado por ella (Greimas, 1987):

(20) Mamacita de mi vida, ya me picó el alacrán; si no quieres que me muera, dame sopitas de pan. (859, estrofa suelta y La indita, Oaxaca)

4. la preponderancia de las aves. Al revisar el cuadro 1, se descubre que, con la excepción de mariposa, el resto de las palabras refiere al campo de las aves, inclusive en sus formas genéricas como ave y pájaro.

De nueva cuenta se puede establecer un tipo de significado cultural en el que el rasgo de la picadura se ha vuelto pertinente para definir y designar a este insecto. 
Una posible respuesta a este fenómeno quizá se deba a lo que se señala en el tercer punto con respecto a las relaciones pre-existentes entre dos elementos de la copla; así como es posible entablar una simbiosis entre miel y abeja, también es posible hacerla entre "aves femeninas"-presas y "aves masculinas"depredadores. En el caso del primer tipo se consignan paloma, pájaro, guacamaya, ${ }^{15}$ calandria, y el segundo se compone de pájaro, guacamaya, ${ }^{16}$ gavilán, pichón y ruiseñor; estas relaciones se deben a procesos de metaforización y creación de estereotipos, de ahí que las aves más delicadas o presas se asocien con características típicas de la mujer y las aves de caza tiendan más al ámbito masculino ${ }^{17}$ (Lara, 2006: 100-101).

La única excepción a lo anterior es el caso de águila, que es usada para referir tanto al amante como a la amada. El uso de este lexema para designar al hombre sigue los patrones mencionados antes ("ave masculina”-depredador); sin embargo, águila femenina se debe a una intención poética de la voz narrativa, la cual busca equiparar a la mujer con la mayor de las aves, la que gana en esplendor y magnificencia, e inclusive ponerla en un estatus de superioridad con respecto al amante, como muestran las siguientes coplas:

\footnotetext{
15 Tanto para pájaro como para guacamaya se usa un adjetivo de color para denotar que se trata de la hembra y no del macho. Normalmente se usan los colores rojo y azul.

${ }^{16}$ Así como en el caso de las aves hembras, los colores que se usan para designar al macho son pinto y colorado.

${ }^{17}$ Un ejemplo claro de este fenómeno de estereotipos se da en la Tragicomedia de Calixto y Melibea. En el primer acto, Calixto tiene que buscar el halcón que ha caído en el huerto de Melibea; sería imposible pensar que el protagonista hubiera perdido una garza o una paloma, pues estas, en principio, no son aves de caza, además de que están lejos del estereotipo del hombre noble aficionado a la cetrería. Con respecto a las aves femeninas, también en la Tragicomedia se da el caso: cuando por fin Calixto y Melibea logran consumar su amor, ella le reclama su premura para quitarle las vestiduras, a lo que este responde: "Para comer la gallina hay que primero desplumarla", es decir, se establece una analogía entre mujer y gallina, ya que ambas comparten características como ser madres, proteger a los hijos y ser la compañera del gallo; este estereotipo tiene gran arraigo en el imaginario popular, ya que en muchas fábulas e incluso películas animadas (Robin Hood de Disney) la gallina representa a la mujer.
} 
(21) Eres un águila real, que en el pico lleva flores, en las alas azucenas y en el corazón amores. (99, El águila real)

(22) Sal como águila triunfante y alza tu rápido vuelo; saca tu espada brillante y corta los hilos del miedo; ya no hagas penar a tu amante. (1089, estrofa suelta, Hidalgo)

Después de este análisis de frecuencias, se lograron algunas aproximaciones a las características del léxico zoológico empleado en las coplas de la sección "El Amante habla a su Amada" del Cancionero Folklórico de México, en especial lo referente a los diez vocablos más usuales, los nahuatlismos empleados y algunas consideraciones sobre la función poética de los insectos como personajes dentro de la narración.

Resulta interesante destacar el peso de las asociaciones metafóricas al momento de hablar de la amada o del amante; ciertos rasgos que se consideran indispensables para el concepto prototípico de tal o cual entidad animal pasan a ser también rasgos humanos y, en algunos casos, ya se han lexicalizado y se trata de metáforas muertas o usos poéticos específicos, como comparar a la mujer con la gallina o al hombre con el mosquito.

\section{La amada zoologizada. Análisis cualitativo}

Es claro que "[...] quienes cantan y escuchan las canciones mexicanas [...] para nada se les ocurriría prescindir mentalmente de la flora y la fauna que pueblan los comienzos de las coplas. Porque ya es hora de recordar que en tales comienzos no solo hay pájaros: también hablan en ellos otros animales favoritos de nuestro folklore y hasta flores, frutos, astros, convertidos todos en mitad seres humanos" (Frenk, 1994: 19). El hecho de que 
se humanice la fauna o bien se zoologice a los seres humanos, según el punto de perspectiva que se quiera tomar, no es algo fuera de lo común; al contrario, este recurso poético es el que vuelve tan especial la copla mexicana, pues no solo da cuenta del imaginario popular en el que se circunscribe el amor - feliz o no- sino que también permite el juego jocoso entre el amante, en su posición de cantante y enunciador, y la amada, público y receptor. ${ }^{18}$

Queda, entonces, la pregunta a responder: ¿qué formas se usan para referir a la amada en tanto entidad que puede ser zoologizada? En seguida se ofrecerán los resultados del análisis del corpus, con especial atención a todas las maneras en que el personaje receptor femenino es designado por la voz poética de la copla.

\subsection{Formas animales para referirse a la amada, indice de frecuencias}

Como ya se ha mencionado, de las 1,995 coplas, solo en 209 se designa a alguna especie del campo de la zoología; ahora bien, de estas, 67 (32.057\%) presentan o bien a un ave o bien a un insecto en lugar de la amada, es decir, utilizan el lexema zoológico para hacer referencia directa a la dama ( $v g r$. "eres el pájaro cú", "mariposa encantada"); en cambio, solo 15 (7.177\%) designan cualidades, dando rasgos de la fauna a la entidad femenina, esto es, decir que tiene el cuerpo o alguna parte corporal similar a la de una especie animal, ya que esos rasgos son pertinentes en el folklore mexicano y forman parte del prototipo de dichas especies (vgr. "cuerpo de urraca", "pico de garza pulida").

\footnotetext{
${ }^{18}$ Uno de los juegos que se da en la lírica popular es el ocultamiento del receptor en la realidad, es decir, el autor-cantante apela a la agudeza mental del receptor para que deduzca a quién dedica las cancioncillas; para ayudar a que el destinatario se sepa aludido o bien el público sepa quién es, el poeta da pistas mediante el uso de hipocorísticos, metáforas semi-dirigidas y analogías entre el antropónimo y algún elemento de la realidad. En el caso de las coplas del amor feliz, esta interacción entre enunciador y receptor es bastante clara, porque se hace explícito el diálogo.
} 
3.1.1 Animales que refieren a la amada de manera directa En el cuadro 2, se hace el cómputo de formas más frecuentes para referir a la amada de manera directa.

\begin{tabular}{c|cc}
\multirow{2}{*}{ Posición } & Animal & $\begin{array}{c}\text { Total de ocurrencias } \\
\text { (absoluto - relativo) }\end{array}$ \\
\hline 1 & Paloma & $41-61.194 \%$ \\
2 & Guacamaya & $5-7.462 \%$ \\
3 & Mariposa & $4-5.970 \%$ \\
4 & Pajarillo barranqueño & $3-4.477 \%$ \\
5 & Venadita & $3-4.477 \%$ \\
6 & Calandria & $2-2.985 \%$ \\
7 & Mariquita & $2-2.985 \%$ \\
& Cuadro 2. Cómputo de formas más frecuentes \\
& para referir a la amada de manera directa
\end{tabular}

A este listado le siguen con una ocurrencia (1.492\%): abejita, águila, ave, cotorra, chachalaca, criatura, grulla, pájaro cú, pichón, pijul, potranquita y tortolita; todas estas voces suman un total de 19 formas distintas para designar de manera directa a la amada, ya sea en voz del autor-cantante o por medio de la interacción entre un animal masculino y uno femenino; $v g r$.

(23) Chaparrita de mi vida, no te hagas la remolona; como al cielo no te subas, yo te he de llevar, paloma. (1292, Cielito, cielito azul)

(24) En una barranca abajo andaba el gavilán perdido en busca de una paloma, la paloma está en su nido: "Anoche dormiste sola, ahora dormirás conmigo". (1578, La leva, San Luis Potosí) 
Ahora bien, es de esperarse que los lexemas no aparezcan solos, sino como núcleos de frases nominales - ya sea en sintagmas del tipo Nominal + Adjetivo, Posesivo + Nominal o Nominal + Adnominal-, o inclusive alguna forma derivada con diminutivos. Los siete primeros de la lista (cuadro 2) presentan las siguientes construcciones:

\section{PAloma:}

\begin{tabular}{c|ccc}
$\begin{array}{c}\text { Forma y } \\
\text { frecuencia }\end{array}$ & Nominal + Adjetivo & $\begin{array}{c}\text { Nominal + } \\
\text { Posesivo }\end{array}$ & $\begin{array}{c}\text { Nominal + } \\
\text { Adnominal }\end{array}$ \\
\hline Paloma (20) & $\begin{array}{c}\text { blanca paloma (4) } \\
\text { paloma blanca (1) } \\
\text { cándida paloma (1) } \\
\text { paloma sagaz (1) }\end{array}$ & $\begin{array}{c}\text { paloma mía } \\
\text { (2) }\end{array}$ & \\
Palomita (20) & $\begin{array}{l}\text { paloma del llano (1) } \\
\text { blanca palomita (1) } \\
\text { palomita blanca (1) } \\
\text { palomita blanca del pico } \\
\text { dorado (1) } \\
\text { palomita consentida (1) } \\
\text { palomita enlutadita (1) } \\
\text { palomita indiana (1) }\end{array}$ & \\
Palomi (1) & palomi (1) & \\
&
\end{tabular}

$2^{\circ}$ Guacamaya

Forma y frecuencia Nominal + Adjetivo(s)

Guacamaya (5)

guacamaya azul turquí (1)

guacamaya colorada (1)

guacamaya linda (1)

\section{$3^{\circ}$ MARIPOSA}

Forma y frecuencia

$$
\text { Nominal + Adjetivo }
$$

Mariposa (3)
Mariposita (1)

mariposa encantada (2)

mariposita dormida (1)

$4^{\circ}$ Pajarillo barranqueño (3): no presenta otras formas. 


\section{$5^{\circ}$ VenAdita}

Forma y frecuencia Nominal + Adjetivo

Venadita (2)

venadita linda (1)

\section{$6^{\circ}$ CALANDRia}

Forma y frecuencia

$($ Adjetivo +$)$ Nominal + Adjetivo

Calandria (2)

rechula mi caladria (1)

calandria amada

7 Mariquita (2): no presenta otras formas.

Con respecto a los lexemas zoológicos de una ocurrencia, se consignaron las siguientes frases en las que aparecen como núcleo: abejita, águila real, preciosa ave lucida, cotorra del pico chueco, prima hermana del perico, chachalaca mía, linda criatura, mi grulla, pájaro cú, pichón celeste, pijul, potranquita y tortolita.

\subsubsection{Cualidades zoológicas de la amada}

El cuadro 3 muestra los diez modos en que se zoologiza a la amada, es decir, se le otorgan cualidades de un animal por medio de la metaforización de alguno de sus rasgos sobresalientes (Santos Domínguez y Espinoza Elorza, 1996; Ullmann, 1972).

\begin{tabular}{|c|c|c|c|}
\hline Posición & Rasgo zoológico & Construcción & $\begin{array}{l}\text { Total de } \\
\text { ocurrencias } \\
\text { (absoluto - } \\
\text { relativo) }\end{array}$ \\
\hline 1 & pico $\rightarrow$ boca (sinécdoque) & $\begin{array}{c}\text { pico de águila real / de garza } \\
\text { pulida / de garza morena / de oro }\end{array}$ & $4-26.666 \%$ \\
\hline 2 & alas $\rightarrow$ brazos (sinécdoque) & cobíjame con tus alas & $2-13.333 \%$ \\
\hline 3 & $\begin{array}{l}\text { gallina } \rightarrow \text { protección } \\
\text { (metaforización) }\end{array}$ & $\begin{array}{l}\text { "No hagas lo de las gallinas, } \\
\text { que tapan cualquier pollito"; } \\
\text { "Arrúllame con tus alas, como la } \\
\text { gallina al huevo" }\end{array}$ & $2-13.333 \%$ \\
\hline 4 & $\begin{array}{l}\text { águila } \rightarrow \text { apariencia } \\
\text { (metaforización) }\end{array}$ & "sal como águila triunfante" & $1-6.666 \%$ \\
\hline
\end{tabular}




\begin{tabular}{|c|c|c|c|}
\hline 5 & $\begin{array}{c}\text { cenzontle } \rightarrow \text { voz } \\
\text { (comparación con la parte) }\end{array}$ & $\begin{array}{c}\text { "cuando el cenzontle canta se me } \\
\text { figura que es tu voz" }\end{array}$ & $1-6.666 \%$ \\
\hline 6 & $\begin{array}{l}\text { cuitlacochita } \rightarrow \text { apariencia } \\
\text { (comparación con el todo) }\end{array}$ & "pareces cuitlacochita" & $1-6.666 \%$ \\
\hline 7 & $\begin{array}{c}\text { mariposa } \rightarrow \text { apariencia } \\
\text { (comparación con el todo) }\end{array}$ & “cual pintada mariposa te luces" & $1-6.666 \%$ \\
\hline 8 & $\begin{array}{c}\text { paloma } \rightarrow \text { apariencia } \\
\text { (comparación con el todo) }\end{array}$ & "pareces paloma" & $1-6.666 \%$ \\
\hline 9 & $\begin{array}{c}\text { sardina } \rightarrow \text { cuerpo }(i ?)^{19} \\
\text { (comparación con el todo) }\end{array}$ & "pariente de la sardina" & $1-6.666 \%$ \\
\hline 10 & $\begin{array}{c}\text { urraca } \rightarrow \text { cuerpo } \\
\text { (comparación con el todo) }\end{array}$ & "Negrita, cuerpo de urraca" & $1-6.666 \%$ \\
\hline
\end{tabular}

\subsection{Análisis semántico de los recursos poéticos zoológicos}

\subsubsection{El caso de las aves}

Las aves, como lo muestran los cuadros 1,2 y 3, constituyen uno de los subgrupos dentro del campo semántico de la zoología que mayor peso tiene dentro del imaginario popular para hacer referencia a la amada o para designar alguna cualidad. En la mayoría de los casos se trata de aves de pequeño o mediano tamaño y que forman parte de nuestro horizonte cultural o incluso de nuestra vida diaria (calandria, cotorra, guacamaya, pichón, paloma y tórtola), y solo en dos casos (águila y grulla) el referente es un animal de tamaño considerable ya un poco alejado de nuestra cotidianeidad citadina. De igual manera, el uso de ciertos lexemas permite ubicar la zona geográfica de origen de la copla. Así, las cuartetas en las que apareció una guacamaya, un pajarillo barranqueño o el pájaro cú se registraron en los estados de Oaxaca y Guerrero, mayoritariamente.

En cuanto a las pequeñas aves, la mayoría hace alusión al carácter delicado e indefenso de estas y, por ende, se relaciona

\footnotetext{
${ }^{19}$ La copla dice: "Eres conchita del mar,/ parienta de la sardina;/ voy a comprarte un collar/ de puritas perlas finas,/ para sacarte a pasear/ delante de las catrinas" (676, Las conchitas, San Luis Potosí); es un caso único y quizá solo se haya usado sardina para lograr la rima en la cuarteta, pero una hipótesis es la de que ser pariente de una sardina implica: 1) son habitantes de la costa y 2) puede ser alguien similar a la sardina por tener el cuerpo pequeño y enjuto.
} 
con el tipo de mujer idealizada que se buscaba en el siglo $\mathrm{xx}$ dentro de un contexto no urbano; en contraste, las de mayor tamaño están relacionadas con la apariencia física de la dama, es decir, debido a su majestuosidad en plumaje o silueta se asemejan a la belleza de la amada, así, grulla equivaldría a una fémina alta y delgada y águila a una con gran presencia y garbo.

Hay dos casos excepcionales en la designación de la amada de manera directa por el amante: cotorra y chachalaca. Las coplas en las que aparecen son las siguientes:

(25) Cotorra del pico chueco, prima hermana del perico, si te pones tu plumita, yo te llevo hasta Tampico. (1308, El toro rabón, Guerrero)

(26) Eres chachalaca mía, que no te puedo olvidar; vente conmigo a la rama, para poderte besar. (1362, La chachalaca, Oaxaca)

Una plausible explicación para el uso de estas dos aves como alusión a la amada es que tanto una como la otra se caracterizan por producir gran escándalo, en el caso de la primera por poder imitar la voz humana, en el segundo por siempre estar graznando incluso al volar; a partir de esta particularidad se hace un enlace con la mujer. Dentro del imaginario popular del siglo xx, una mujer se definía por hablar mucho, chismear y hacer arguende, ${ }^{20}$ de ahí que se pueda hacer uso de estas aves tan poco prototípicas para designar a la amada, en tanto formas más irónicas o jocosas.

\subsubsection{El caso de los insectos y mamíferos}

El segundo subgrupo zoológico con más apariciones es el de los insectos: mariposa, mariquita y abejita. El primero se explica

\footnotetext{
${ }^{20}$ Este es un caso de total lexicalización, pues el DLE y el DEM (ss.vv.) tienen entre sus acepciones el designar a "una persona (muy) habladora".
} 
por la relación entre apariencia y belleza, ya que, como sucede con las aves pequeñas, la mariposa se vincula con la mujer por ser delicada, inofensiva y frágil; el término mariquita sigue el mismo patrón de asociación cognitiva, aunque hay que recalcar un detalle peculiar en ambos casos: se trata de palabras cuyo étimo hace alusión a un antropónimo, posiblemente el nombre de la amada, ya que el primer insecto se deriva de la construcción "María se posa" > "Mari posa" > mariposa, y el segundo es un diminutivo de marica, que, sin ser coincidencia, es un diminutivo de María (DLE, s.v.).

El tercer y último grupo utilizado por la voz poética para designar a la amada es el de los mamíferos, representado por potranquita y venadita. Sobre esto habría que hacer un par de consideraciones: a) son formas en diminutivo, potranquita < potranca < potro 'caballo de cuatro años de edad' y venadita $<$ venado 'animal indomesticable y de caza' (DLE, s.v.), con lo que más que hacer una reducción del tamaño, se busca lograr una aproximación entre el enunciador y el receptor; b) ambos lexemas hacen referencia a mamíferos que en estado salvaje son indomables, en otras palabras, se caracterizan por su carácter un tanto agresivo o que son reacios a ser sometidos por un agente, pero no por ello pierden su valor o carecen de la capacidad de maravillar a quien los mira por sus características físicas y gran fuerza.

A partir de esta característica y bajo el postulado de la relación cognitiva entre mujer y animal, se deduce que utilizar estos dos términos implica una alusión a un tipo de mujer similar en carácter a estos dos cuadrúpedos, y que al mismo tiempo se presenta como un reto que el amante asumirá en su conquista de la amada. $^{21}$

\footnotetext{
${ }^{21}$ En el caso de venadita es más claro el esquema conceptual de cazador-presa/trofeo por amante-amada. Cabe recordar que este esquema es de la Edad Media, época en la que se consideraba a la dama como un trofeo por el que el caballero tenía que luchar contra otros caballeros o criaturas, como los dragones; $v g r$. los libros de caballerías hispánicos que narran las hazañas de caballeros con tal de ganar el galardón de la princesa (Zifar, Amadís, Palmerín, Lisuarte, Don Quijote).
} 


\subsubsection{Zoologización de rasgos corporales}

Las partes del cuerpo de la mujer que se presentan asociadas con algún elemento zoológico son básicamente cuatro: boca, brazos, voz y cuerpo/apariencia.

En el primero, el de la boca como pico, tiene dos interpretaciones: 1) el pico se asemeja a la boca en la función de besar ${ }^{22}$ y 2) pico como medio por el cual sale el canto, es decir, la "voz" del ave cuando canta. En este sentido se puede hablar de metaforización zoológica, similar a los casos de cola de caballo y patas de gallo (Santos Domínguez y Espinoza Elorza, 1996; Ullmann, 1972). Patrón similar sigue el esquema brazos-alas, con la salvedad de que adquiere el rasgo de 'protección' gracias a que el animal con el que es comparada la mujer es la gallina. Aquí se daría un esquema de triada gallina-huevo-alas en el que los participantes interactúan bajo el marco de la protección. ${ }^{23}$

En cuanto a la voz y a la apariencia corporal, se puede decir que entran en juego dos facultades sensoriales: la audición y la vista, que son también las de mayor frecuencia en las Coplas del amor feliz, junto con el tacto (Fernández Sepúlveda, 2013). Entonces, no es desestimable considerar que a partir de la percepción de la realidad y, en el orbe amoroso, de la otra persona por medio de estos dos sentidos es como se hacen las analogías: audición-voz ergo voz-canto de ave y vista-cuerpo/apariencia ergo cuerpo humano y cuerpo zoológico. Ahora bien, es importante tener presente que si bien la primera zoologización es clara y no presenta problemas, pues es de uso vigente en el imaginario popular del siglo XxI, al existir expresiones como voz de trino o canta como las aves o parece pajarito no para de cantar, en lo referente al cuerpo, la analogía no es tan ostensible porque el ejemplo de sardina implica un gran esfuerzo cognitivo para

\footnotetext{
${ }^{22}$ Recuérdense las expresiones "Parar la trompa" y "Tás trompuda o quieres beso", que siguen este mismo esquema, pero con la diferencia de que la analogía se hace entre la boca humana y el hocico de ciertos mamíferos, en especial el cerdo.

${ }^{23}$ Otros ejemplos que manifiestan este esquema actancial de protección gallina/ madre-huevo/hijo es: "Eres la mamá de los pollitos" o "Pareces la mamá de los pollitos", ambas expresiones suelen ser usadas para referir a una mujer que protege a otros con singular dedicación.
} 
poder establecer una relación, y en el de urraca no es sino hasta que uno ve una imagen del ave que entiende lo que implica tener el cuerpo como ella (figura 1 ), ${ }^{24}$ además de que la urraca es confundida con el cuervo. Esto se debe a que la mayoría de los mexicanos que viven en la urbe no distinguen entre una y el otro, ese conocimiento de mundo se ha perdido, o nunca fue adquirido.

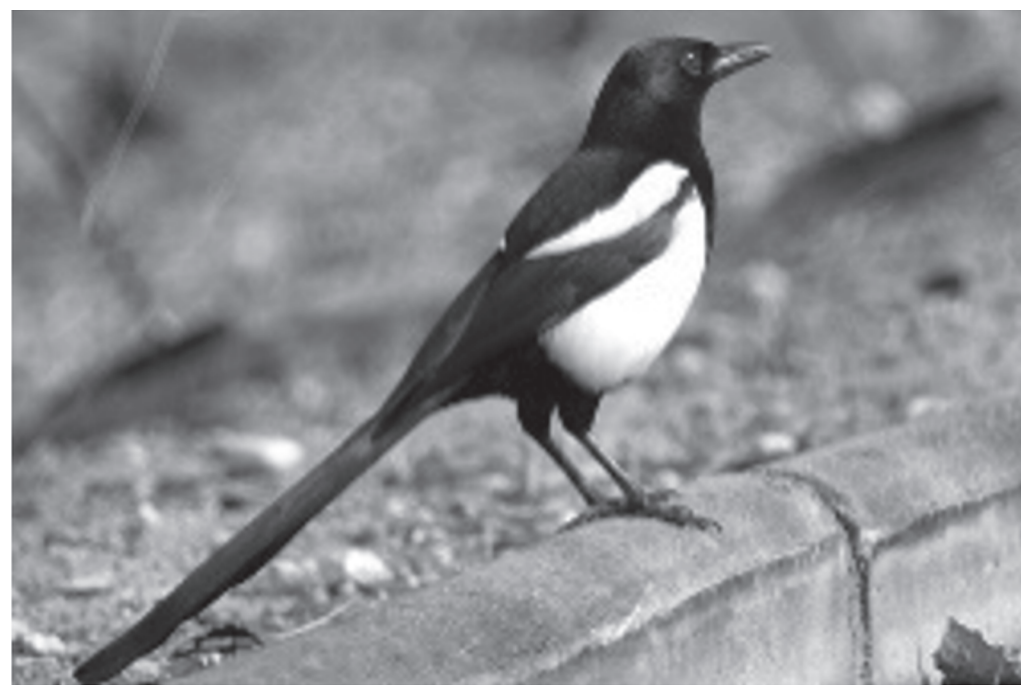

Figura 1. Urraca. Fuente: <http://waste.ideal.es/fotos2/picapica29.jpg>

\section{A manera de conclusión o sobre la vigencia del léxico zoológico amoroso}

Para concluir este análisis resta abordar un elemento importante para comprender el léxico zoológico amoroso: su vigencia y vitalidad. Entendiendo por vigencia el uso, en la actualidad, de las formas con que se designa a la amada o alguna cualidad

\footnotetext{
${ }^{24}$ Confieso que este fue mi caso. No podía entender cuál era el atractivo de una mujer que tuviera el cuerpo como urraca, sino hasta que busqué una fotografía en internet. Al ver la imagen, las mujeres a las que pregunté aceptaron que no les parecía del todo ofensiva la expresión, al contrario, comentaron que era una ave elegante y bonita.
} 
de ella dentro de la comunidad mexicana - con especial atención en el habla cotidiana y las formas léxicas que usan las parejas actualmente para referirse a uno y el otro-; y vitalidad como el hecho de que las formas zoológicas siguen siendo productivas, aún son metáforas.

Para poder determinar lo anterior en las coplas del tema "El Amante habla a la Amada" del Cancionero Folklórico de México se realizó una breve encuesta de carácter perceptual (véase nota 6) sobre si dichas formas aún eran reconocibles entre la comunidad tanto masculina como femenina del siglo xxI y si eran usadas para los mismos fines - apelar de manera directa a la amada o designar una cualidad que tuviese y fuese similar a la de algún miembro de la zoología. Desafortunadamente los resultados indicaron que ninguna de las expresiones zoológicas del Cancionero para designar a la amada se encuentra entre el repertorio de elementos que conforman el léxico amoroso de hoy; en oposición a lo encontrado en el corpus, puede decirse que actualmente solo se emplean formas como (mi) amor, mi vida, bebé, baby o bae cuando se habla de la persona amada (sea mujer $\mathrm{u}$ hombre, de manera directa o indirecta) y cuando se hace uso de un lexema del campo semántico zoológico suele ser en casos particulares de juego entre la pareja ${ }^{25}$ o para referir a la pareja de alguien más. La explicación de este fenómeno es que, si bien el Cancionero es una recopilación exhaustiva de la expresión poética popular de México, ya ha pasado cerca de medio siglo desde su aparición $\mathrm{y}$, con ello, se ha dado un salto generacional y un cambio importante en el imaginario popular, aunado al hecho de que la tradición de la lírica popular se ha perdido, pues no es frecuente encontrar cancioneros, papeles volantes o personas que canten coplas, coplitas, villancicos u otras formas populares de poesía.

En todo caso, esto vuelve a confirmar la tesis de Matoré (1953) de que el léxico es reflejo de una civilización, de su cultura en un tiempo determinado, y que se manifiesta en palabras

\footnotetext{
${ }^{25}$ Lo interesante de la encuesta fue que solo para referirse a los hombres se usaron algunas formas de tratamiento zoológico, vgr. osito, leoncito y lobito. En cuanto a las mujeres, solo hubo un caso: libélula.
} 
clave y palabras testigo ${ }^{26}$ cabe ahora preguntarse si dentro de un futuro y volviendo a hacer un cancionero folklórico de México ¿qué tipo de canciones o lírica popular sería pertinente recopilar?, ¿reggaetón o corridos de banda quizás?, ¿qué cambios culturales habrá?, ¿qué formas de tratamiento en el ámbito amoroso serán usadas por las nuevas generaciones?

\section{Bibliografía}

Fernández Sepúlveda, María Andrea (2013), “Los verbos de percepción sensorial en Las coplas del amor feliz del Cancionero floklórico de México", Anuario de Letras. Lingüística y Filología, I:1, pp. 9-30.

Frenk, Margit (1985), Las jarchas mozárabes y los comienzos de la lírica románica, México, El Colegio de México.

Frenk, Margit (1994), Charla de pájaros, o, Las aves en la poesía folklórica mexicana: discurso, México, Universidad Nacional Autónoma de México.

Frenk, Margit (dir.) (1998), Cancionero folklórico de México, tomo 1: "Coplas del amor feliz", México, El Colegio de México.

Greimas, Algirdas Julius (1987), Semántica estructural. Investigación metodológica, traducción de Alfredo de la Fuente, Madrid, Gredos (Biblioteca Románica Hispánica, III. Manuales, 27).

Lara, Luis Fernando (2006), Curso de lexicología, México, El Colegio de México.

Lara, Luis Fernando (dir.) (2010), Diccionario del español de México (DEM), 2 vols., México, El Colegio de México.

\footnotetext{
${ }^{26}$ Matoré señala que las palabras testigo son el símbolo de una situación social, económica o estética, pues añaden el concepto de peso dentro del vocabulario (1953: 65) y las palabras clave son de una naturaleza más abstracta en la que la sociedad reconoce en ellas su ideal (1953: 68); en el caso del Cancionero, todas las formas que designan una entidad zoológica son las palabras testigo de las palabras clave amor feliz.
} 
Lara, Luis Fernando (2016), Teoría semántica y método lexicográfico, México, El Colegio de México (Serie Estudios de Lingüística y Literatura, LXVI).

Levinson, Stephen C. (1985), Pragmatics, Cambridge, Cambridge University Press (Cambridge Textbooks in Linguistics, 13).

Masera, Mariana (2007), "Los recursos de la copla: simbolismo y paralelismo", en A. González (ed.), La Copla en México, México, El Colegio de México, pp. 189-203.

Matoré, Georges (1953), La méthode en lexicologie: domaine français, París, Dider.

Real Academia Española, Diccionario de la lengua española (DLE) <www.dle.rae.es> [consultado el 9 de octubre de 2017].

Santos Domínguez, Luis Antonio y Rosa María Espinoza Elorza (1996), Manual de semántica histórica, Madrid, Síntesis (Textos de Apoyo. Lingüística, 21).

Soler Arechalde, María Ángeles (1998), "Glosario: voces y construcciones regionales y de la cultura rural", en $\mathrm{M}$. Frenk (coord.), Cancionero Folklórico de México, tomo 5, "Antología, glosario, índices", México, El Colegio de México.

Ullmann, Stephen (1972), Semántica. Introducción a la ciencia del significado, traducción de Juan Martín Ruiz-Werner, Madrid, Aguilar (Colección Cultura e Historia).

\section{Alfonso Padrón Martínez}

Egresado de la licenciatura en Lengua y Literaturas Hispánicas en la Facultad de Filosofía y Letras de la Universidad Nacional Autónoma de México. Actualmente estudia el doctorado en Lingüística en el Centro de Estudios Lingüísticos y Literarios en El Colegio de México.

Ha sido ayudante de Investigador Nacional Nivel III en los proyectos "Políticas del lenguaje en México" e "Historia Sociolingüística de México" y Ayudante de profesor en las ma- 
terias "Lexicología y Semántica 1” y "Lexicología y Semántica 2", ambas impartidas en la Facultad de Filosofía y Letras de la Universidad Nacional Autónoma de México.

Sus temas de interés y líneas de investigación son el latín medieval, la filología románica, la lexicología y los estudios interdisciplinarios entre literatura y lingüística. 